\title{
Nanomedicines: Future Against Infections
}

\section{Narayanasamy $\mathbf{P}^{*}$}

Department of Pathology and Microbiology, College of Medicine, University of Nebraska Medical Center, Omaha, Nebraska, USA

The World Health Organization estimates that around 1.5 billion people are currently infected with latent Mycobacterial tuberculosis (MTB). However, each year, 8 million people develop active disease and 3 million die. Approximately $20 \%$ of these cases are multiple drug resistant (MDR-TB), resistant to the main first-line drugs isoniazid and rifampin, and $2 \%$ are extensively drug resistant (XDR-TB), resistant to isoniazid, rifampin, fluoroquinolones and at least one of three secondline drugs (amikacin, kanamycin, or capreomycin). Despite, no new classes of anti-TB drugs or drug formulations have been introduced clinically since the 1980's [1].

Over and above Human Immunodeficiency Virus (HIV) is a global infectious disease causing significant morbidities and mortality within an infected human host. These all have contributed to an alarming millions of infected people worldwide [2]. Further complicating disease outcomes are combined HIV and MTB co-infections. In addition the frequent occurrence of HIV-MTB co-infection can favor development of MDR-TB and XDR-TB. Thus, improvements in drug access and simplified treatment regimens are needed immediately. In this context, the design and development of long-acting formulations of traditional anti-MTB and anti-HIV drugs is of great interest [3]. We posit that one way this can be achieved is through nanoformulated drugs [4].

Conjointly, Gram-negative bacteria are common causes of IntraAbdominal Infections (IAIs), Urinary Tract Infections (UTIs), nosocomial pneumonia, and bacteremia. Escherichia coli (E.coli) and Pseudomonas aeruginosa ( $P$. aeruginosa) are important pathogens in the hospital setting, accounting for $27 \%$ of all pathogens and $50 \%$ of all Gram-negative pathogens causing healthcare-associated. Gramnegative bacteria are resistant to multiple drugs and are increasingly resistant to most available antibiotics. These bacteria have built-in abilities to find new ways to be resistant and can pass along genetic materials that allow other bacteria to become drug-resistant as well. Antibiotic-resistant infections pose considerable challenges to clinicians in relation to diagnosis, treatment, and infection control, as well as considerable costs. The estimates of the healthcare costs to the world economy for antibiotic-resistant infections have risen as high as $\$ 40$ billion. Treatment options to meet this challenge are increasingly limited. There is a critical need for new antibiotics and techniques to meet the needs of patients now and in the future.
Generally treatment of bacterial or viral disease requires long time and daily prescription in addition to drug resistance. For example tuberculosis treatment has to be continued for minimum 6-12 months' time period and HIV treatment should be carried out for years. In that regard development of non-resistant and long acting drugs are increasingly in need.

Loading antibiotics in nanoparticles will restore their ability to destroy bacteria including that have acquired resistance to them. Furthermore, nanoparticles loaded with antibiotics have been shown to increase the concentration of antibiotics at the site of bacteriumantibiotic interaction in sub-cellular level, and it facilitatesthe binding of antibiotics to bacteria in the process of killing the bacteria [4]. Nanoparticles also can have sustained drug release property for a certain time period depending on its property [4]. The sustained drug releasing nanoparticle can reduce the number of drug intake e.g. drug can be taken once in a week or two weeks. Nanomedicines also shows importance in treating neurodegenerative disorders because of its ability to pass through blood brain barrier [5]. Most importantly, such drug formulations have unquestioned translational potential.

\section{References}

1. Narayanasamy P, Eoh H, Brennan PJ, Crick DC (2010) Synthesis of 4-diphosphocytidyl-2-C-methyl-D-erythritol 2-phosphate and kinetic studies of Mycobacterium tuberculosis IspF. Chem Biol 17: 117-122.

2. Kadiu I, Narayanasamy P, Dash PK, Zhang W, Gendelman HE (2012) Biochemical and biologic characterization of exosomes and microvesicles as facilitators of HIV-1 infection in macrophages. J Immunol 189: 744-754.

3. Edagwa BJ, Narayanasamy P (2013) Synthesis of chirally pure 1-deoxy-dxylulose-5-phosphate : A substrate for IspC assay to determine $M$. tb inhibitor. Chem Sci J 4.

4. Edagwa BJ, Guo D, Puligujja P, Chen H, McMillan J, et al. (2014) Long-acting antituberculous therapeutic nanoparticles target macrophage endosomes. FASEB journal :official publication of the Federation of American Societies for Experimental Biology.

5. Epstein AA, Narayanasamy P, Dash PK, High R, Bathena SP, et al. (2013) Combinatorial assessments of brain tissue metabolomics and histopathology in rodent models of human immunodeficiency virus infection. J Neuroimmune Pharmacol 8: 1224-1238.
*Corresponding author: Narayanasamy P, UNMC Department of Pathology and Microbiology985900 Nebraska Medical Center, Omaha, USA, Tel: 402-559-9120. Fax: 402-559-6018; E-mail: p.narayanasamy@unmc.edu

Received September 22, 2014; Accepted September 24, 2014; Published September 30, 2014

Citation: Narayanasamy P (2014) Nanomedicines: Future Against Infections Chem Sci J 5: e105. doi: 10.4172/2150-3494.1000e105

Copyright: (c) 2014 Narayanasamy P. This is an open-access article distributed under the terms of the Creative Commons Attribution License, which permits unrestricted use, distribution, and reproduction in any medium, provided the original author and source are credited. 